\title{
Ozonolysis of trimethylamine exchanged with typical ammonium salts in the particle phase
}

\author{
Yanli Ge ${ }^{1,3}$, Yongchun Liu*1,2,3, Biwu Chu ${ }^{1,2,3}$, Hong He ${ }^{1,2,3}$, Tianzeng Chen ${ }^{1,3}$,
}

\author{
Shaoxin Wang ${ }^{1}$, Wei Wei ${ }^{4}$, Shuiyuan Cheng ${ }^{4}$
}

1. State Key Joint Laboratory of Environment Simulation and Pollution Control,

Research Center for Eco-Environmental Sciences, Chinese Academy of Sciences, Beijing, 100085, China

2. Center for Excellence in Urban Atmospheric Environment, Institute of Urban Environment, Chinese Academy of Sciences, Xiamen 361021, China.

3. University of Chinese Academy of Sciences, Beijing, 100049, China

4. Key Laboratory of Beijing on Regional Air Pollution Control, Beijing University of Technology, Beijing 100022, China

13 pages, 2 tables, 6 figures

\section{Theory of 2DCOS and data interpretation.}

The theory, principle and applications of two-dimensional correlation spectra (2DCOS) had been carefully described elsewhere ${ }^{1,2}$. Generally, 2DCOS is an analytical technique based on time-resolved detection of IR signals to study molecular interactions. In 2DCOS, a spectrum is obtained as a function of two independent wavenumbers. For generation of a 2D IR spectrum, an experimental approach based on the detection of various relaxation processes which are much slower than vibrational relaxations but are closely associated with molecular-scale phenomena, is needed to get the dynamic spectrum of the system. And then a mathematical manipulation of such dynamic spectra generates a useful set of 2D IR correlation spectra, including a synchronous and an asynchronous spectrum. The synchronous one represents the simultaneous or coincidental changes of spectral intensities measured at two independent wavenumbers. It is symmetric with respect to the diagonal line, peaks found at the diagonal position at coordinates are referred to as autocorrelation peaks, while cross-correlation peaks are 
not at the diagonal position. Autocorrelation peaks either increase or decrease together as functions of time during the observation period. On the other hand, the negative sign of cross-peaks indicates that one of the spectral intensities is increasing while the other is decreasing. In an asynchronous spectrum, it represents sequential, or unsynchronized, changes of spectral intensities. There is no autocorrelation peaks in the asynchronous spectrum and just consisting only cross-correlation peaks located at off-diagonal positions, which develops only if the intensities of two dynamic spectral intensities vary out of phase with each other ${ }^{3,4}$. For example, if two wavenumbers exist in synchronous spectrum and are absent in the asynchronous one, they might have positive relations, belonging to the same species or vibration mode. If they only showed in the asynchronous one, they have no correlation from one another whether they are in the synchronous spectrum or not ${ }^{4}$. Following the rules above, data in our study can be analyzed.

As shown in Figure S3a and c, several autocorrelation peaks, namely, the positive peaks at $3750,3390,2760,1655,1415,1129,1080$ and $688 \mathrm{~cm}^{-1}$, were observed during ozone oxidation of TMA-exchanged $\left(\mathrm{NH}_{4}\right)_{2} \mathrm{SO}_{4}$. This means that the concentrations of the relevant species increased as a function of reaction time. At the same time, the negative peaks at $1201(1170-1237)$ and $849 \mathrm{~cm}^{-1}$ indicate that the concentration of these species decreased as a function of reaction time. ${ }^{5}$ This is consistent with the analysis of the one-dimensional IR spectra as discussed above. In Figure S3b and d, cross-correlation peaks with non-zero value were observed at $(688,3340),(820,3340)$, (960, 3400), (1080, 3390), (1290, 3390), (1420, 3390), (1560, 3390), (1710, 3390), (2580, 3390), (2760, 3390), (2854, 3390), (2894, 3390), (3210, 3390), (877, 921), (877, 974), (877, 1424), (877, 1080), (877, 1424), (877, 2580), (877, 1564), (877, 1660), (877, 1750), (962, 1424), (1080, 1140), (1080, 1357), (1080, 1412), (1080, 1529), (1080, 1642), (1080, 1668), (1080, 1754), (1080, 1780), (1080, 2684), (1080, 2760), (1140, 1290), (1140, 2580), (1140, 1424), (1140, 1560), (1365, 1543), (1424, 1486), (1486, $1560),(1726,2771)$ and so on. For some bands, the frequencies identified in 2DCOS deviated slightly from those observed in Figure 3 because of the different spectral resolution. Besides the absorption bands observed in Figure 3, several new bands can 
be identified in Figure S3. For example, the band at $877 \mathrm{~cm}^{-1}$ can be assigned to $v_{\mathrm{s}}(\mathrm{CN})$ in $\mathrm{DMF}^{6}$ or nitromethane ${ }^{7}$. The band at $1660 \mathrm{~cm}^{-1}$, which is ascribed to $v_{\mathrm{s}}(\mathrm{C}=\mathrm{N})$ in $\mathrm{CH}_{3} \mathrm{~N}=\mathrm{CH}_{2},{ }^{8}$ is observable in Figure S3d. The band at $2760 \mathrm{~cm}^{-1}$ is related to the combination mode of $v_{\mathrm{s}}(\mathrm{C}=\mathrm{O})$ and $\tau(\mathrm{COH})$ (twisting vibration of $\mathrm{COH}$ ) in $\mathrm{HCOOH}^{9}$. The band at $2894 \mathrm{~cm}^{-1}$ can be assigned to $v_{\mathrm{s}}(\mathrm{CH})$ in $\mathrm{HCOOH}^{9}$. As discussed above, the band around $1750 \mathrm{~cm}^{-1}$ may originate from formic acid and/or formaldehyde. The crosscorrelation peak at $\left(1750 \mathrm{~cm}^{-1}, 2720 \mathrm{~cm}^{-1}\right)$ was observed in Figure S3a, while it was unobservable (with a zero value) in Figure S3b. At the same time, the cross-correlation peak at $\left(1750 \mathrm{~cm}^{-1}, 1211 \mathrm{~cm}^{-1}\right)$ was also observed in Figure $\mathrm{S} 3 \mathrm{c}$, while it was absent in Figure S3d. This means that $1750 \mathrm{~cm}^{-1}\left(v_{\mathrm{s}}(\mathrm{CO})\right)$ is correlated to both $2720\left(v_{\mathrm{s}}(\mathrm{CH})\right.$ in formaldehyde $)$ and $1211 \mathrm{~cm}^{-1}(\delta(\mathrm{C}-\mathrm{OH})$ in formic acid $)$ according to the principles of 2DCOS analysis ${ }^{5,10,11}$. Therefore, both formaldehyde and formic acid can be confirmed as products. 
Table S1 Reaction conditions in displacement and ozonolysis reactions.

\begin{tabular}{ccccccc}
\hline & & \multicolumn{2}{c}{$\begin{array}{c}\text { Conditions in } \\
\text { displacement reaction }\end{array}$} & $\begin{array}{c}\text { Conditions in } \\
\text { ozonolysis reaction }\end{array}$ \\
\cline { 5 - 8 } Substrates & Phase state & $\begin{array}{c}\text { Sample } \\
\text { mass (mg) }\end{array}$ & $\begin{array}{c}\text { TMA } \\
\text { concentration } \\
(\mathrm{ppm})\end{array}$ & $\begin{array}{c}\mathrm{RH} \\
(\%)\end{array}$ & $\begin{array}{c}\mathrm{O}_{3} \\
\text { concentration } \\
(\mathrm{ppb})\end{array}$ & $\begin{array}{c}\mathrm{RH} \\
(\%)\end{array}$ \\
\hline$\left(\mathrm{NH}_{4}\right)_{2} \mathrm{SO}_{4}$ & Amorphous & 2.2 & $\sim 385$ & 21 & 127 & 12 \\
$\mathrm{NH}_{4} \mathrm{HSO}_{4}$ & Amorphous & 15.3 & $\sim 385$ & 21 & 203 & 12 \\
$\mathrm{NH}_{4} \mathrm{NO}_{3}$ & Amorphous & 12.0 & $\sim 385$ & 21 & 412 & 12 \\
$\mathrm{NH}_{4} \mathrm{Cl}$ & Amorphous & 6.6 & $\sim 385$ & 21 & 267 & 12 \\
\hline
\end{tabular}


Table S2. Assignments of the IR bands.

\begin{tabular}{|c|c|c|c|c|c|c|c|c|}
\hline \multirow[b]{2}{*}{ Compounds } & \multicolumn{4}{|c|}{ Observed frequency $\left(\mathrm{cm}^{-1}\right)$} & \multirow{2}{*}{$\begin{array}{l}\text { Calculated frequency } \\
\qquad\left(\mathrm{cm}^{-1}\right)\end{array}$} & \multirow{2}{*}{$\begin{array}{l}\text { Frequency in } \\
\text { literatures }\left(\mathrm{cm}^{-}\right. \\
\left.{ }^{1}\right)\end{array}$} & \multirow[b]{2}{*}{ Vibration model } & \multirow[b]{2}{*}{ Literature } \\
\hline & $\left(\mathrm{NH}_{4}\right)_{2} \mathrm{SO}_{4}$ & $\mathrm{NH}_{4} \mathrm{HSO}_{4}$ & $\mathrm{NH}_{4} \mathrm{NO}_{3}$ & $\mathrm{NH}_{4} \mathrm{Cl}$ & & & & \\
\hline \multirow{7}{*}{ TMA } & 2960 & 2960 & - & 2990 & 3016 & 2980 & $v_{\mathrm{as}}\left(\mathrm{CH}_{3}\right)$ & \multirow{7}{*}{12} \\
\hline & 2870 & 2870 & - & 2886 & 2838 & 2874 & $v_{\mathrm{s}}\left(\mathrm{CH}_{3}\right)$ & \\
\hline & $2300-2700$ & $2300-2700$ & $2300-2700$ & $2300-2700$ & - & $2236-2735$ & $\begin{array}{c}\text { Overtone/combination } \\
\text { bands of }-\mathrm{CH}_{3} \text { and } \\
\mathrm{NC}_{3} \text { groups }\end{array}$ & \\
\hline & 1486 & 1482 & 1484 & 1477 & 1472 & 1478 & $\delta\left(\mathrm{CH}_{3}\right)$ & \\
\hline & 1446 & 1446 & 1446 & 1446 & 1443 & 1443 & $\delta\left(\mathrm{CH}_{3}\right)$ & \\
\hline & $985-1290$ & $985-1290$ & $985-1290$ & $985-1290$ & $1029,1043,1173,1272$ & $1103-1275$ & $\rho\left(\mathrm{CH}_{3}\right)$ & \\
\hline & 845 & 845 & 816 & 816 & - & 849 & $2 \delta\left(\mathrm{NC}_{3}\right)$ & \\
\hline \multirow{3}{*}{$\mathrm{H}_{2} \mathrm{O}$} & 3400 & 3440 & 3471 & 3400 & - & 3380 & $v_{\mathrm{s}}(\mathrm{OH})$ & \multirow{3}{*}{13} \\
\hline & 3287 & - & 3287 & 3287 & - & & $\begin{array}{c}v_{\mathrm{s}}(\mathrm{OH}) \text { of hydrogen } \\
\text { bonded } \mathrm{OH}\end{array}$ & \\
\hline & 1640 & 1640 & 1640 & 1640 & - & 1650 & $\delta(\mathrm{OH})$ & \\
\hline \multirow{5}{*}{$\mathrm{HCOOH}$} & 2894 & & & & 2889 & 2899 & $v_{\mathrm{s}}(\mathrm{CH})$ & \multirow{5}{*}{9} \\
\hline & 2760 & & & & - & 2760 & $v_{\mathrm{s}}(\mathrm{C}=\mathrm{O})+\tau(\mathrm{COH})$ & \\
\hline & 1750 & 1764 & 1759 & & 1814 & 1767,1808 & $v_{\mathrm{s}}(\mathrm{C}=\mathrm{O})$ & \\
\hline & 1211 & & & 1245 & 1240 & 1215,1244 & $\delta(\mathrm{C}-\mathrm{OH})$ & \\
\hline & 962 & 978 & 973 & 976 & 1008 & 980 & $w_{\text {oop }}(\mathrm{CH})$ & \\
\hline $\mathrm{HCHO}$ & 2836 & & & 2834 & 2868 & 2843 & $v_{\mathrm{as}}\left(\mathrm{CH}_{2}\right)$ & 14 \\
\hline
\end{tabular}




\begin{tabular}{|c|c|c|c|c|c|c|c|c|}
\hline & 2720 & & & 2727 & 2812 & 2782 & $v_{\mathrm{s}}(\mathrm{CH})$ & \\
\hline & 1750 & 1736 & 1769 & & 1768 & 1746 & $v_{\mathrm{s}}(\mathrm{C}=\mathrm{O})$ & \\
\hline \multirow{7}{*}{$\left(\mathrm{CH}_{3}\right)_{2} \mathrm{NCHO}$} & $1660-1680$ & 1685 & 1688 & $1660-1680$ & 1708 & 1685 & $v_{\mathrm{s}}(\mathrm{C}=\mathrm{O})$ & \multirow{7}{*}{6} \\
\hline & 1513 & 1512 & 1515 & 1502 & 1503 & 1512 & $\delta\left(\mathrm{CH}_{3}\right)+v_{\mathrm{s}}(\mathrm{CN})$ & \\
\hline & 1484 & 1460 & 1472 & 1458 & 1464 & 1460 & $\delta\left(\mathrm{CH}_{3}\right)$ & \\
\hline & 1280 & 1285 & 1268 & 1280,1245 & 1268 & 1242 & $v_{\mathrm{s}}(\mathrm{CN})$ & \\
\hline & 1129 & & 1125 & 1120 & 1144 & 1099 & $\mathrm{r}\left(\mathrm{CH}_{3}\right)$ & \\
\hline & 1078 & & 1076 & 1082 & 1099 & 1064 & $\mathrm{r}\left(\mathrm{CH}_{3}\right)$ & \\
\hline & 877 & 878 & 852 & & 847 & 870 & $v_{\mathrm{s}}(\mathrm{CN})$ & \\
\hline \multirow{5}{*}{$\mathrm{CH}_{3} \mathrm{~N}=\mathrm{CH}_{2}$} & 1660 & 1686 & 1657 & $1660-1767$ & 1690 & 1676,1661 & $v_{\mathrm{s}}(\mathrm{C}=\mathrm{N})$ & \multirow{5}{*}{8} \\
\hline & 1484 & 1492 & & 1459 & 1469 & $1472-1492$ & $\delta\left(\mathrm{CH}_{3}\right)$ & \\
\hline & 1415 & & 1419 & 1425 & 1438 & - & $\beta(\mathrm{C}-\mathrm{H})$ & \\
\hline & 1129 & 1131 & 1126 & 1120 & 1112 & - & $\mathrm{r}\left(\mathrm{CH}_{3}\right)$ & \\
\hline & 899 & & 902,934 & 939 & 938 & 939 & $v_{\mathrm{s}}(\mathrm{CN})$ & \\
\hline \multirow{5}{*}{$\mathrm{CH}_{3} \mathrm{NO}_{2}$} & 1580 & 1561 & 1566 & & 1580 & 1570 & $v_{\mathrm{as}}\left(\mathrm{NO}_{2}\right)$ & \multirow{5}{*}{7} \\
\hline & 1415 & & 1419 & 1425 & 1439 & 1438 & $\delta\left(\mathrm{CH}_{3}\right)$ & \\
\hline & 1365 & 1370 & 1367 & & 1365 & 1381 & $v_{\mathrm{s}}\left(\mathrm{NO}_{2}\right)$ & \\
\hline & 1129 & 1131 & 1126 & 1120 & 1106 & 1125 & $\mathrm{r}\left(\mathrm{CH}_{3}\right)$ & \\
\hline & 885 & 879 & & 915 & 902 & 918 & $v_{\mathrm{s}}(\mathrm{CN})$ & \\
\hline $\mathrm{CO}_{2}$ & 2375 & 2360 & 2368 & & - & 2361 & $v_{\mathrm{s}}(\mathrm{OCO})$ & 15 \\
\hline \multirow{5}{*}{$\mathrm{CH}_{3} \mathrm{~N}(\mathrm{OH}) \mathrm{CHO}$} & 3756 & 3743 & 3758 & & 3677 & - & $v_{\mathrm{s}}(\mathrm{OH})$ & \multirow{5}{*}{-} \\
\hline & 1750 & 1735 & 1714 & & 1716 & - & $v_{\mathrm{s}}(\mathrm{CO})$ & \\
\hline & 1484 & 1493 & 1472 & & 1475 & - & $\delta\left(\mathrm{CH}_{3}\right)$ & \\
\hline & 1140 & 1132 & 1137 & & 1148 & - & $\mathrm{r}\left(\mathrm{CH}_{3}\right)$ & \\
\hline & 820 & & & 833 & 821 & - & $v_{\mathrm{s}}(\mathrm{NCO})$ & \\
\hline
\end{tabular}




\begin{tabular}{|c|c|c|c|c|c|c|c|c|}
\hline \multirow{3}{*}{$\mathrm{CH}_{3} \mathrm{NHOH}$} & 3756 & 3749 & 3758 & & 3730 & - & $v_{\mathrm{s}}(\mathrm{OH})$ \\
\cline { 2 - 8 } & 1365 & 1371 & 1367 & & 1322 & - & $\delta(\mathrm{OH})$ \\
\cline { 2 - 8 } & 962 & 977 & 973 & 976 & 951 & - & $\delta(\mathrm{NH})$ \\
\cline { 2 - 8 } & 820 & 808 & & 833 & 821 & - & $v_{\mathrm{s}}(\mathrm{NCO})$ \\
\hline
\end{tabular}



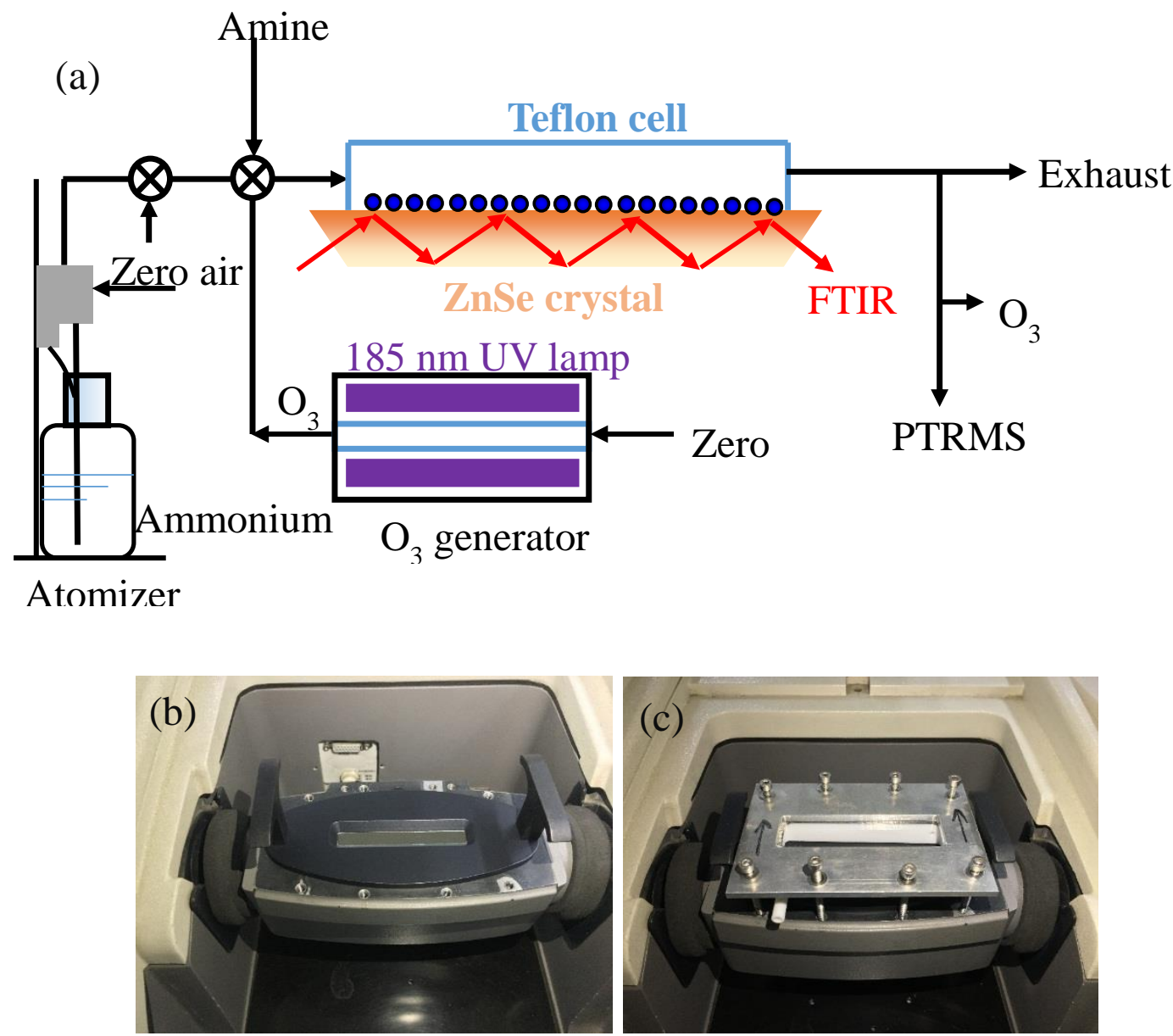

Figure S1. (a) Experimental setup; (b) and (c) pictures of the ATR reactor used in this study. The reaction chamber consisted with a ZnSe crystal, a sealed Teflon wall and a quart window. An entry and an exit port were on the opposite side of the Teflon wall. The surface-to-volume ratio was $2 \mathrm{~cm}^{-1}$ with a volume of $44 \mathrm{~cm}^{3}$. The residence time of the gases in the reactor was $26 \mathrm{~s}$ with a total flow rate of $100 \mathrm{~mL} / \mathrm{min}$ before the reactor was sealed. All the reactions were performed in the dark by covering the quart window with aluminium foil.
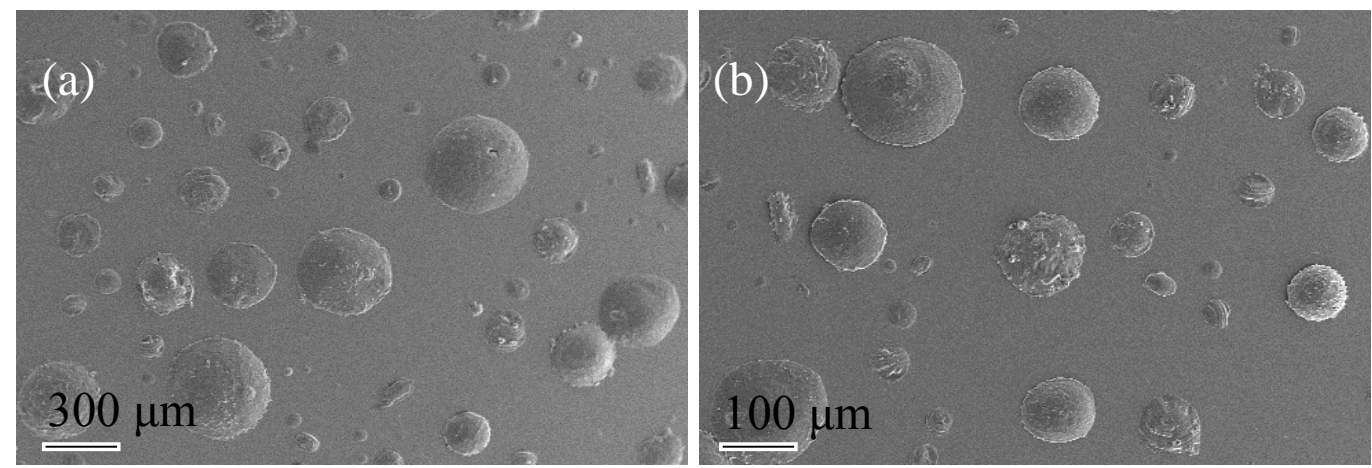

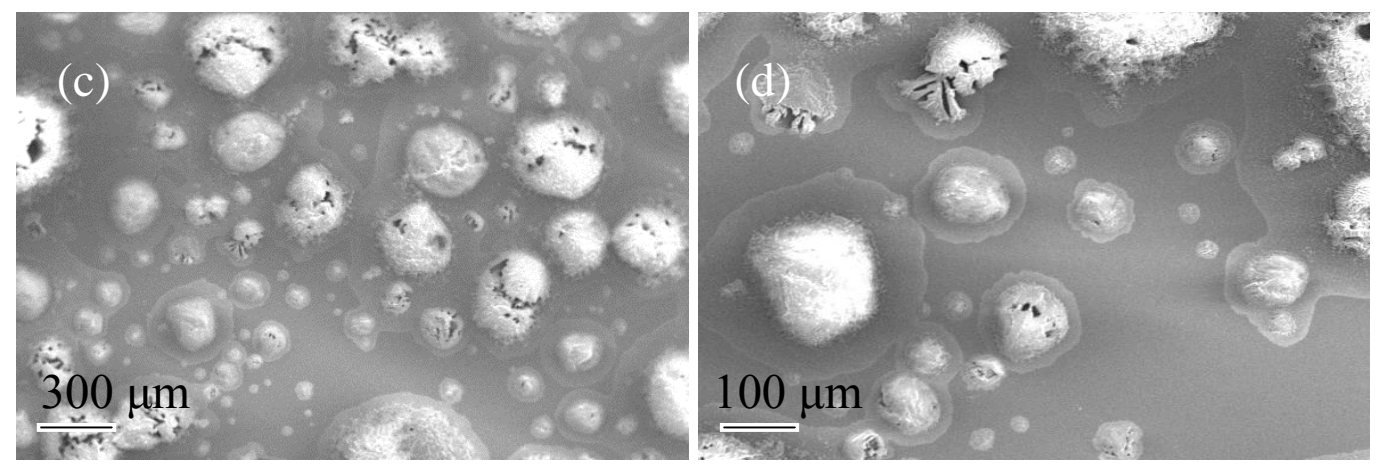

Figure S2 SEM micrographs of (a) and (b) for ammonium sulfate; (c) and (d) for aminium sulfate particles.

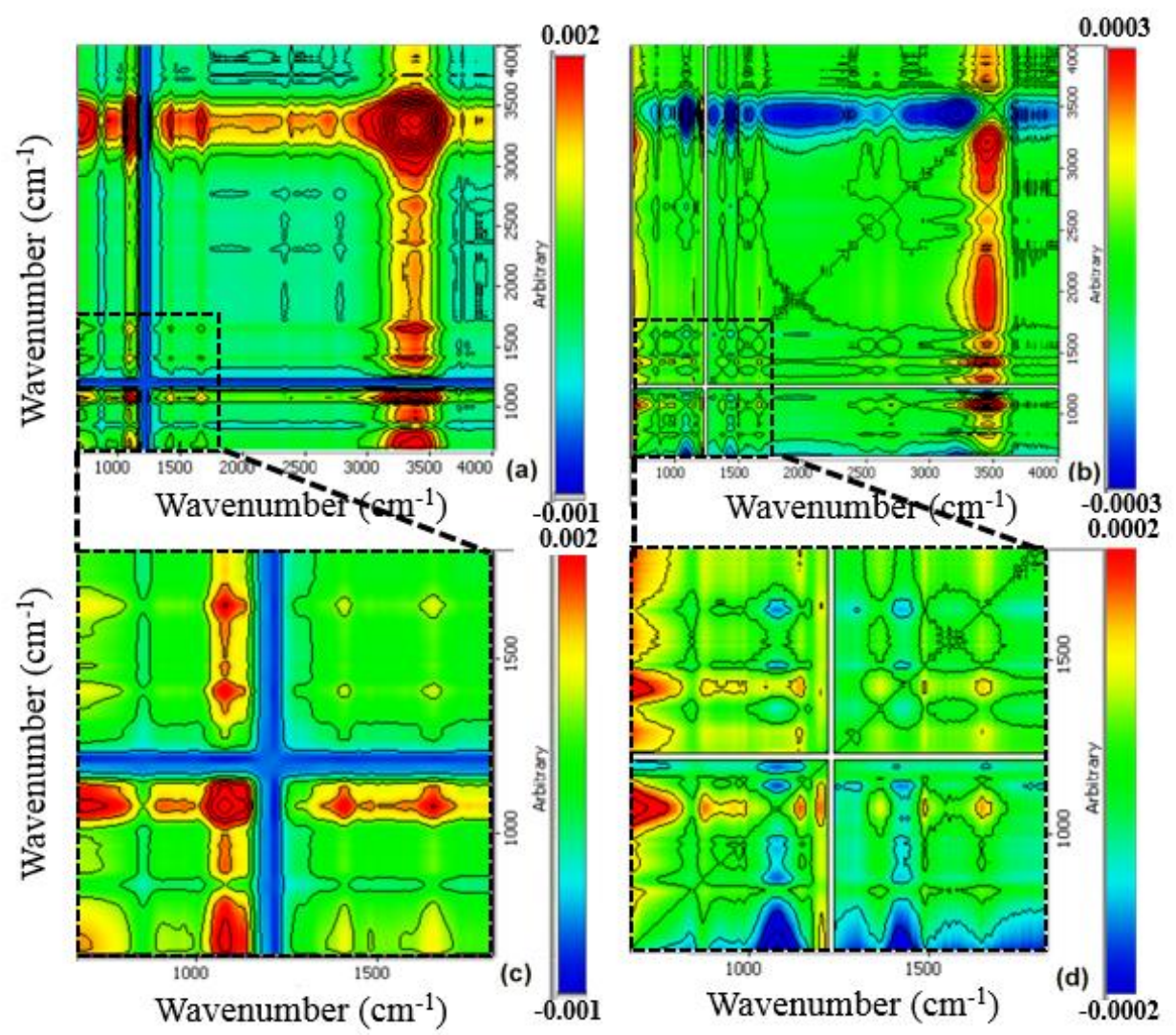

Figure S3. (a) Synchronous and (b) asynchronous two-dimensional correlation spectra during $\mathrm{O}_{3}$ oxidation of TMA exchanged $\left(\mathrm{NH}_{4}\right)_{2} \mathrm{SO}_{4}$; (c) the magnified synchronous 2DCOS and asynchronous 2DCOS in the range of $650 \sim 1800 \mathrm{~cm}^{-1}$. 


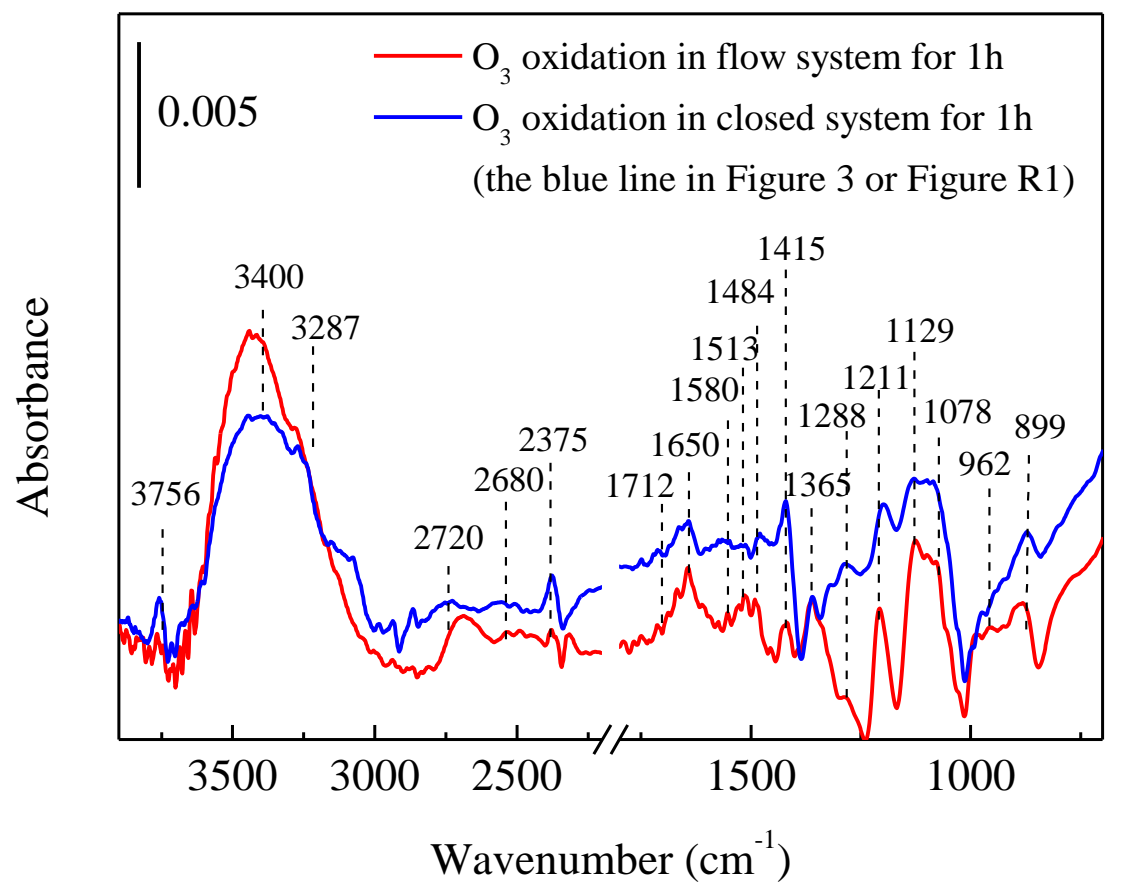

Figure S4 Comparison between the in situ FT-IR spectra during ozone oxidation of TMA exchanged $\left(\mathrm{NH}_{4}\right)_{2} \mathrm{SO}_{4}$ in the flow system (the red line) and the closed system (the blue line). The initial $\mathrm{O}_{3}$ concentration was $127 \mathrm{ppb}$. The flow rate was $100 \mathrm{ml} / \mathrm{min}$ in the flow system. The blue line in this figure is the same as the blue line in Figure 3. 


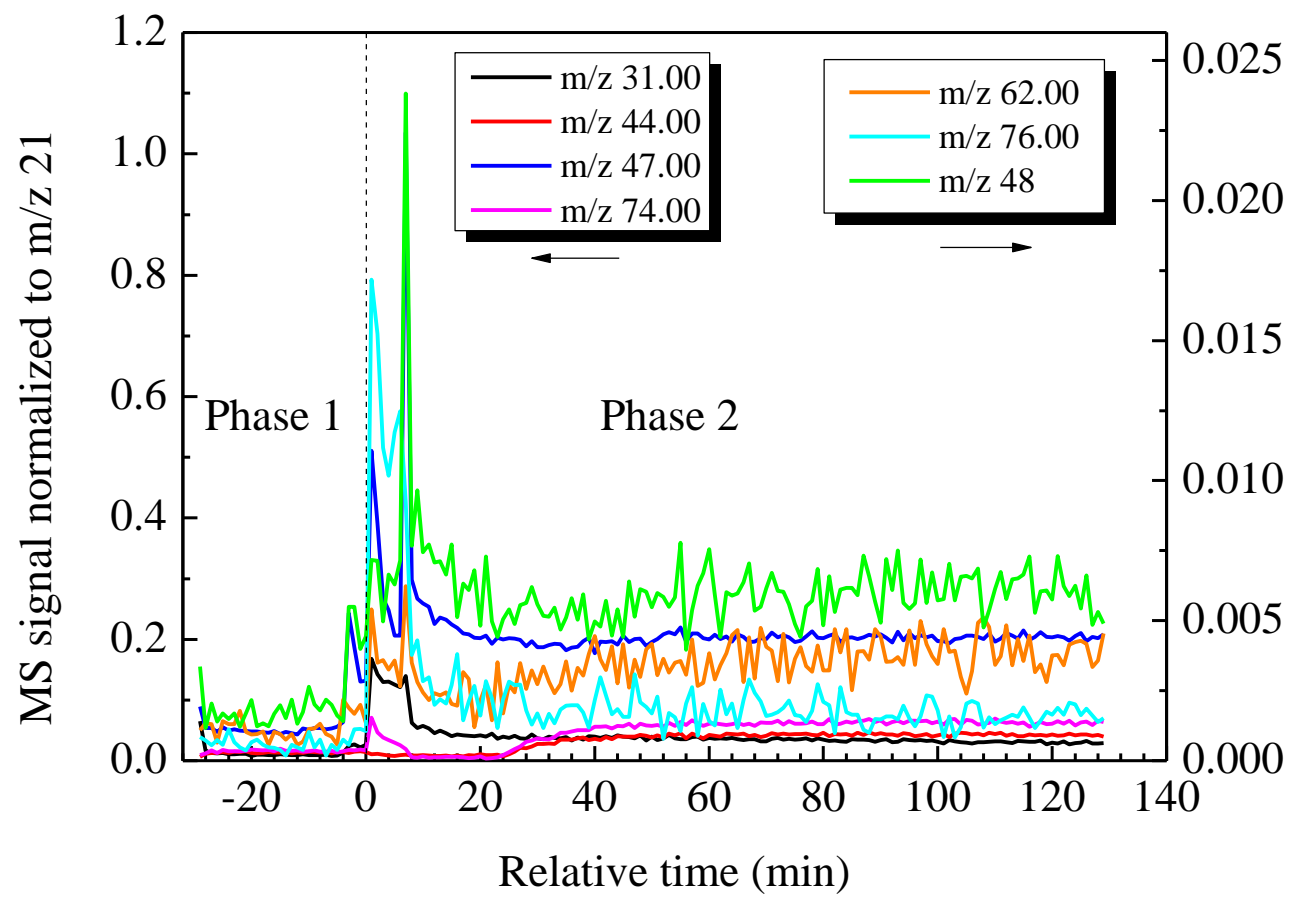

Figure S5. Concentration changes of the products measured by the PTR-MS. Phase 1: purging with zero air before $\mathrm{O}_{3}$ oxidation of TMA exchanged $\left(\mathrm{NH}_{4}\right) \mathrm{SO}_{4}$ to remove adsorbed and gas-phase TMA in the chamber. Phase 2: purging with zero air after $\mathrm{O}_{3}$ oxidation of TMA exchanged $\left(\mathrm{NH}_{4}\right) \mathrm{SO}_{4}$. 
(A)

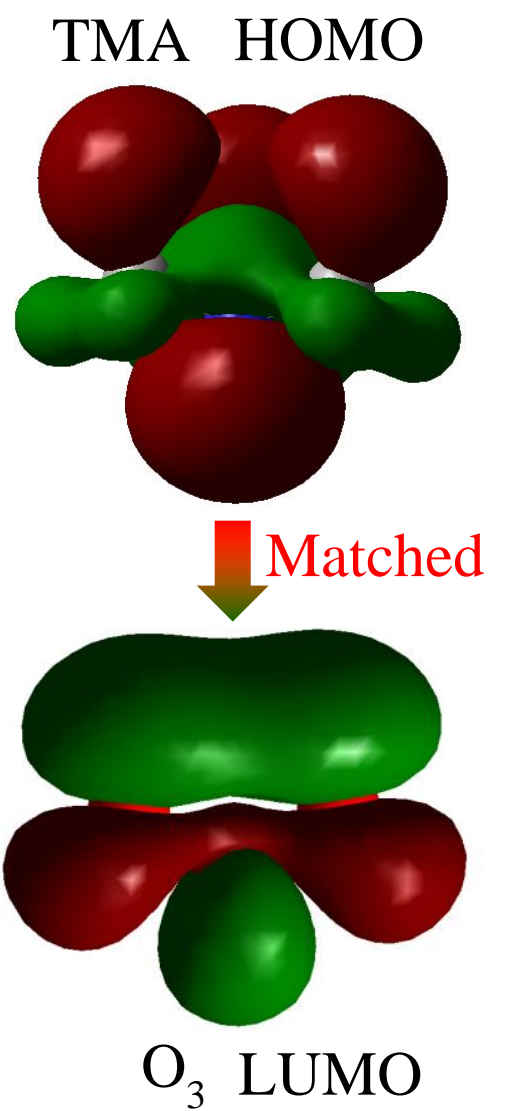

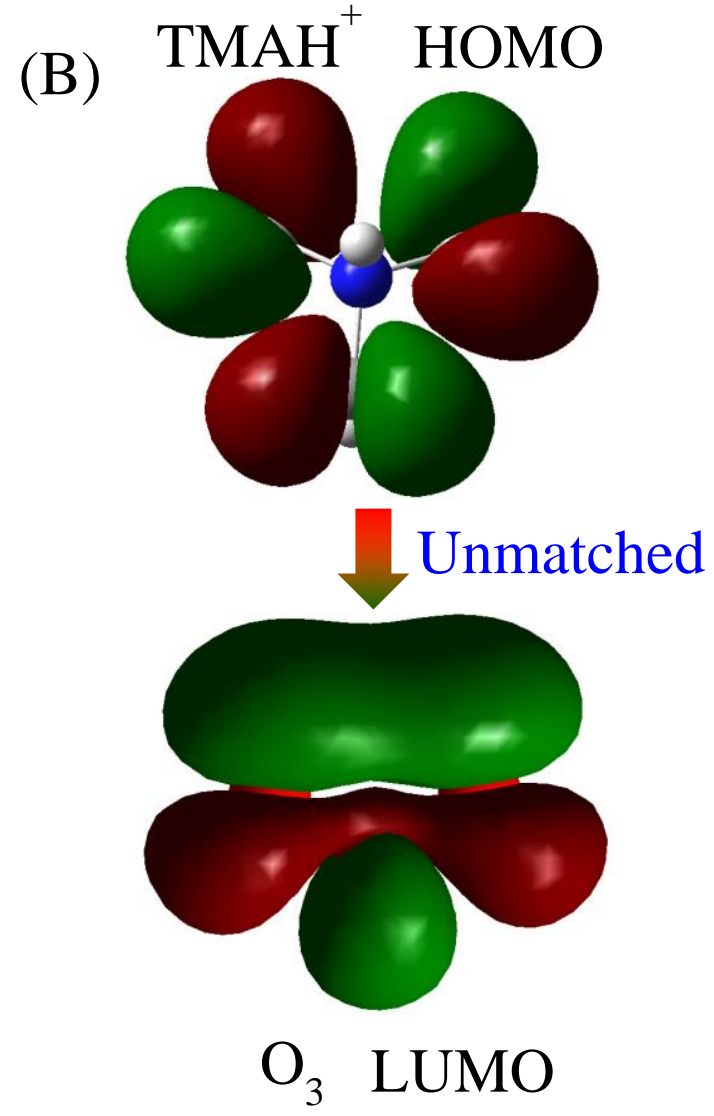

Figure S6. Molecular orbit analysis for (A) TMA and $\mathrm{O}_{3}$ (B) $\mathrm{TMAH}^{+}$and $\mathrm{O}_{3}$.

\section{References:}

1. Ozaki, Y.; Sasic, S.; Tanaka, T.; Noda, I., Two-dimensional correlation spectroscopy: Principle and recent theoretical development. Bull. Chem. Soc. Jpn 2001, 74, (1), 1-17.

2. Noda, I., Two-dimensional infrared (2d ir) spectroscopy: theory and applications. Appl. Spectrosc. 1990, 44, (4), 550-561.

3. DeVane, R.; Space, B.; Perry, A.; Neipert, C.; Ridley, C.; Keyes, T., A time correlation function theory of two-dimensional infrared spectroscopy with applications to liquid water. J. Chem. Phys. 2004, $121,(8), 3688-3701$.

4. Noda, I.; Dowrey, A. E.; Marcott, C., Recent developments in two-dimensional infrared (2D-IR) correlation spectroscopy. Appl. Spectrosc. 1993, 47, (9), 1317-1323.

5. Harrington, P. d. B.; Urbas, A.; Tandler, P. J., Two-dimensional correlation analysis. Chemom. Intell. Laborat. Syst. 2000, 50, (2), 149-174.

6. Durgaprasad, G.; Sathyanarayana, D. N.; Patel, C. C., Infrared spectra and normal vibrations of n,ndimethylformamide and N,N-dimethylthioformamide. Bull. Chem. Soc. Jpn. 1971, 44, (2), 316-322.

7. Itoh, K.; Iwa, A.; Uriu, Y.; Kadokura, K., Infrared absorption spectroscopic and DFT calculation studies on the adsorption structures of nitromethane on the single crystals of Cu and Ag. Surf. Sci. 2008, $602,(13), 2148-2156$.

8. Lindley, C., The kinetics of dimethylamino radical reactions in simulated atmospheres: The 
formation of dimethylnitrosamine and dimethylnitramine. Ph.D. Dissertation, Ohio State University, Columbus, $\mathrm{OH}, 1978$.

9. Pettersson, M.; Lundell, J.; Khriachtchev, L.; Räsänen, M., IR spectrum of the other rotamer of formic acid, cis-HCOOH. J. Am. Chem. Soc. 1997, 119, (48), 11715-11716.

10. Cho, M., Coherent two-dimensional optical spectroscopy. Chem. Rev. 2008, 108, 1331-1418.

11. Noda, I., Two-dimensional correlation spectroscopy — Biannual survey 2007-2009. J. Mol. Struct. 2010, 974, 3-24.

12. Murphy, W. F.; Zerbetto, F.; Duncan, J. L.; McKean, D. C., Vibrational spectrum and harmonic force field of trimethylamine. J. Phys. Chem. 1993, 97, (3), 581-595.

13. Onasch, T. B.; Siefert, R. L.; Brooks, S. D.; Prenni, A. J.; Murray, B.; Wilson, M. A.; Tolbert, M. A., Infrared spectroscopic study of the deliquescence and efflorescence of ammonium sulfate aerosol as a function of temperature. J. Geophys. Res.-Atmos. 1999, 104, (D17), 21317-21326.

14. Busca, G.; Lamotte, J.; Lavalley, J. C.; Lorenzelli, V., FT-IR study of the adsorption and transformation of formaldehyde on oxide surfaces. J. Am. Chem. Soc. 1987, 109, (17), 5197-5202.

15. Liu, Y.; He, H.; Xu, W.; Yu, Y., Mechanism of heterogeneous reaction of carbonyl sulfide on magnesium oxide. J. Phys. Chem. A 2007, 111, 4333-4339. 